\title{
Evaluation of Regressive Analysis Based Sea Surface Temperature Estimation Accuracy with NCEP/GDAS Data
}

\author{
Kohei Arai ${ }^{1}$ \\ Graduate School of Science and Engineering \\ Saga University \\ Saga City, Japan
}

\begin{abstract}
In order to evaluate the skin surface temperature (SSST) estimation accuracy with MODIS data, 84 of MODIS scenes together with the match-up data of NCEP/GDAS are used. Through regressive analysis, it is found that 0.305 to $0.417 \mathrm{~K}$ of RMSE can be achieved. Furthermore, it also is found that band 29 is effective for atmospheric correction (30.6 to $38.8 \%$ of estimation accuracy improvement). If single coefficient set for the regressive equation is used for all the cases, SSST estimation accuracy is around $1.969 \mathrm{~K}$ so that the specific coefficient set for the five different cases have to be set.
\end{abstract}

Keywords- Thermal infrared radiometer; Skin sea surface temperature; Regressive analysis; Split window method; NCEP/GDAS; MODTRAN; Terra and AQUA/MODIS.

\section{INTRODUCTION}

The required skin sea surface temperature estimation accuracy is better than $0.25 \mathrm{~K}$ for radiation energy budget analysis, global warming study and so on [1]. Skin sea surface temperature (SSST) is defined as the temperature radiation from the sea surface (approximately less than $20 \mu \mathrm{m}$ in depth from the surface) and is distinct with the Mixed layer sea surface temperature (MSST) based on the temperature radiation from the sea surface (about $10 \mathrm{~m}$ in depth from the surface) and also is different from the Bulk sea surface temperature (BSST) which is based on the temperature radiation from just below the skin [2]. In order to estimate SSST, (a) atmospheric influences which are mainly due to water vapor followed by aerosols for the atmospheric window channels [3], (b) cloud contamination, (c) emissivity changes mainly due to white caps, or forms followed by limb darkening due to changes of path length in accordance with scanning angle changes should be corrected [4]-[8].

One of the atmospheric corrections is split window method which is represented by Multi Channel Sea Surface Temperature (MCSST) estimation method [9]. In the MCSST method, $10 \mu \mathrm{m}$ of atmospheric window is split into more than two channels. The atmospheric influences are different among the split channels so that it is capable to estimate atmospheric influence by using the difference. Through a regressive analysis between the estimated SSST with acquired channels of satellite onboard thermal infrared radiometer (TIR) data and the corresponding match-up truth data such as buoy or shipment data (Bulk temperature) with some errors, all the required coefficients for the regressive equation are determined. Thus SSST is estimated with the regressive equation if the newly acquired TIR data is put into the regressive equation. On the other hand, the method for improvement of SSST estimation accuracy by means of linearized inversion of radiative transfer equation (RTE) is proposed [10] and also the method for solving RTE more accurately based on iterative method is proposed [11],[12]. RTE is expressed with Fred-Holm type of integral equation with a variety of parameters. Such RTE can be solved with linear and/or Non-Linear inversion methods. Integral equation can be linearized then RTE can be solved by using linear inversion method and also can be solved iteratively. The former and the later are called Linearized inversion and NonLinear iteration, respectively.

In accordance with MODTRAN [13], the following 5 cases of the ocean areas (Latitude) and the seasons are selected, (a)Sub-Arctic Summer, (b)Sub-Arctic Winter, (c)Mid-Latitude Summer, (d)Mid-Latitude Winter, (e)Tropic. The regressive analysis is made by using a match-up data set of MODIS data and NCEP/GDAS (Global Data Assimilation Model [14], 1 degree mesh data of air temperature, relative humidity, ozone, cloud, precipitable water for the sphere with the altitude ranges from 1000 to $100 \mathrm{hPa}$ ) data. The regressive error in terms of Root Mean Square Error (RMSE) and regressive coefficients are calculated.

Firstly, major specification of MODIS is introduced together with atmospheric characteristics such as transparency, water vapor profile and aerosol profile derived from MODTRAN. Secondly, the method for regressive analysis is described followed by the procedure of the preparation of match-up data derived from NCEP/GDAS and MODIS data together with cloud masking. Thirdly, the results from the regressive analysis are shown followed by the results from the comparative study on regressive equations. Finally, major conclusions are discussed.

\section{PROPOSED METHOD}

\section{A. MODIS onboard Terra and Aqua satellites}

MODIS/TIR onboard Terra and AQUA satellites is moderate spatial resolution $(\mathrm{IFOV}=1 \mathrm{k} \mathrm{m})$ of thermal infrared radiometer with the swath width of $2400 \mathrm{~km}$ and consists of 3 
channels of radiometer which covers the wavelength region shown in Table 1.

\section{B. Atmospheric Model Used}

The atmospheric transmittance for the wavelength region for the typical atmospheric models in accordance with MODTRAN 4.0, Tropic, Mid-Latitude Summer and winter, Sub-Arctic Summer and winter are shown in Fig.1.
TABLE I. WAVELENGTH COVERAGE OF MODIS

\begin{tabular}{|l|c|l|l|l|}
\hline Cloud Properties & 29 & $8.400-8.700$ & $9.58(300 \mathrm{~K})$ & 0.05 \\
\hline $\begin{array}{l}\text { Surface/Cloud } \\
\text { Temperature }\end{array}$ & 31 & $10.780-11.280$ & $9.55(300 \mathrm{~K})$ & 0.05 \\
\cline { 2 - 5 } & 32 & $11.770-12.270$ & $8.94(300 \mathrm{~K})$ & 0.05 \\
\hline
\end{tabular}

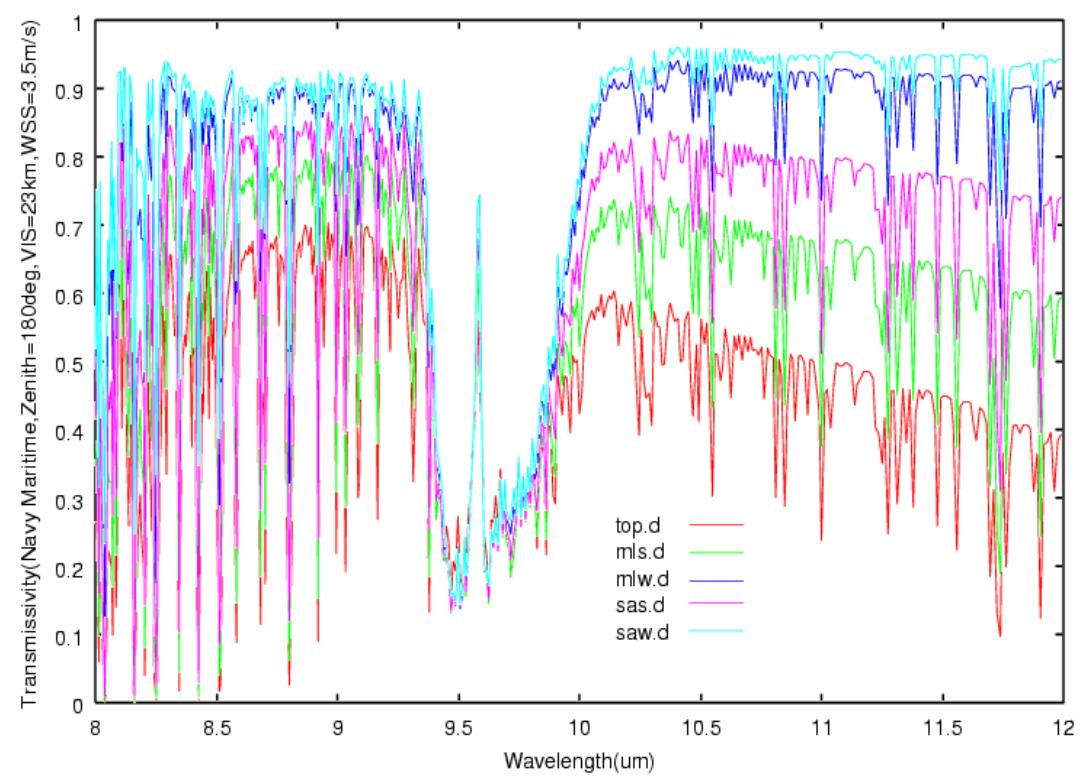

Figure 1 Transmittance for the typical atmospheric models

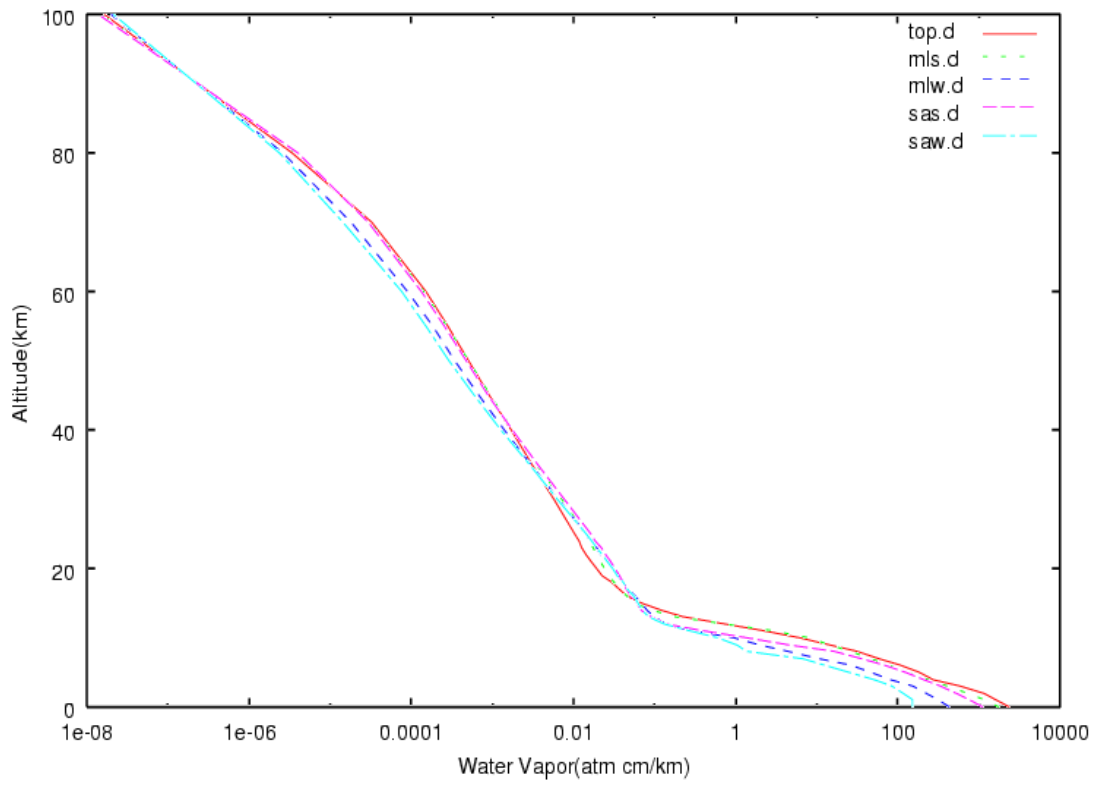

Fig2 The vertical profile of the water vapor for the typical atmospheric models. 


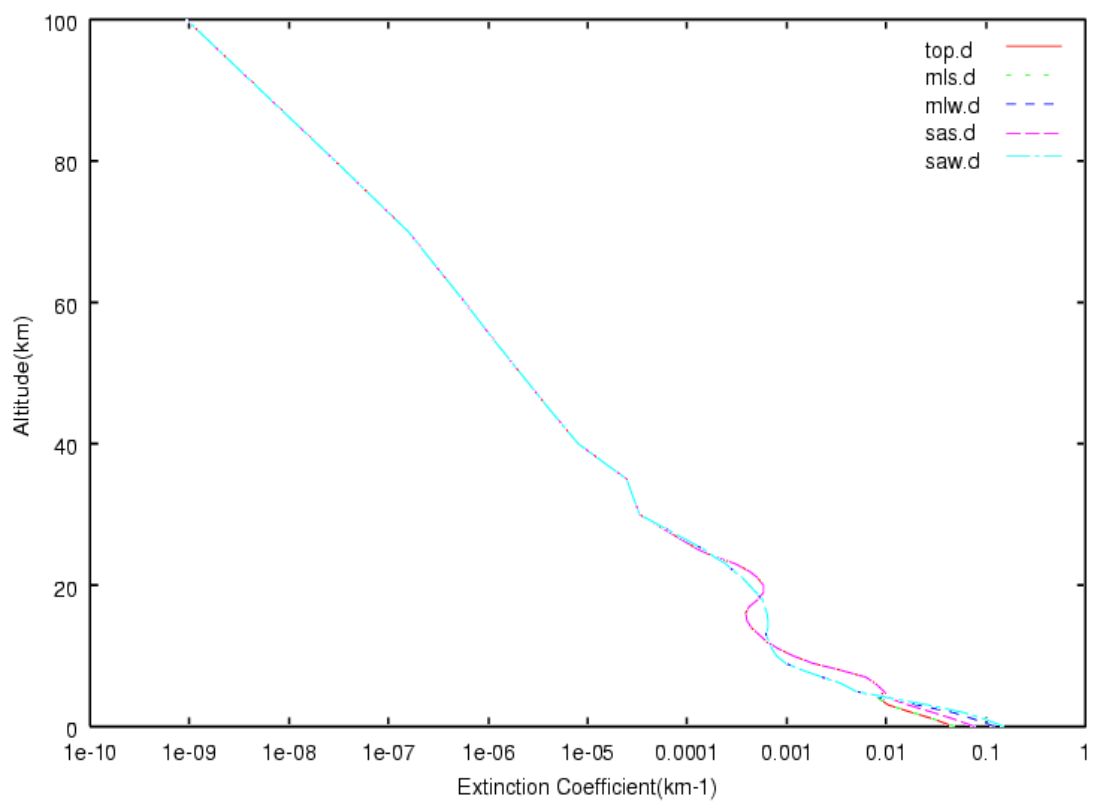

Fig.3 The vertical profile of the aerosol extinction coefficient for the typical atmospheric models

In this calculation, aerosol type and meteorological range are set to rural and $23 \mathrm{~km}$, respectively while the observation angle is set at 0 degree of zenith angle, namely, nadir looking situation. The vertical profiles of water vapor content in the atmosphere (in unit of atm $\mathrm{cm} / \mathrm{km}$ ) and aerosol extinction coefficient (in unit of $\mathrm{km}^{-1}$ ) are shown in Fig.2 and 3, respectively.

The Tropic shows lowest transmittance followed by MidLatitude Summer, Sub-Arctic Summer, Mid-Latitude Winter and Sub-Arctic Winter while the Tropic shows largest water vapor content in the atmosphere followed by Mid-Latitude Summer, Sub-Arctic Summer, Mid-Latitude Winter and SubArctic Winter.

The most dominant factor for atmospheric influence in this wavelength region is water vapor followed by aerosol so that vertical profiles have to be clarified. Relatively good MODIS data for the Sub-Arctic Winter could not be found so that (1) Tropic, (2) Mid-Latitude Summer, (3) Mid-Latitude Winter and (4) Sub-Arctic Summer were selected for the analysis.

\section{Regressive Analysis}

The following simple linear regressive equation between NCEP/GDAS derived SSST and the physical temperature estimated with MODIS Level 1B product of data is assumed,

\footnotetext{
$\mathrm{SSST}=\mathrm{C}_{1}+\mathrm{C}_{2} * \mathrm{~T}_{30}+\mathrm{C}_{3} *\left(\mathrm{~T}_{30}-\mathrm{T}_{31}\right)+\mathrm{C}_{4} *(\sec (\theta)-1) *\left(\mathrm{~T}_{30}-\mathrm{T}_{31}\right)$

$+\mathrm{C}_{5} *\left(\mathrm{~T}_{30}-\mathrm{T}_{29}\right) *(\sec (\theta)-1) *\left(\mathrm{~T}_{30}-\mathrm{T}_{29}\right)$

where Ti is the brightness temperature of the channel i, $\theta$ is the solar zenith angle. Through a regressive analysis, $\mathrm{Ci}$ for each case is estimated as well as regression error, Root Mean Square Error (RMSE) which is corresponding to the SSST estimation error. In this connection, the swath width of MODIS is $60 \mathrm{~km}$ while the grid size of NCEP/GDAS is 1 degree so that the averaged $\mathrm{Ti}$ over full scene of MODIS $(2400 \mathrm{~km})$ is calculated and put into the equation (1) together with the linearly interpolated NCEP/GDAS data at the scene center of the MODIS data which become SSST in the equation (1). In accordance with ATBD 25 (SST algorithm [15]), SST is estimated with the following equation,

$$
\mathrm{SST}=\mathrm{a}_{0}+\mathrm{a}_{1} \mathrm{~T}_{1}+\mathrm{a}_{2}\left(\mathrm{~T}_{1}-\mathrm{T}_{2}\right) \mathrm{T}_{\mathrm{b}}+\mathrm{a}_{3}(\sec (\theta)-1)
$$

where $\mathrm{Tb}$ is MCSST [9]. The proposed regressive equation uses band 29 of brightness temperature influenced by water vapor. It is very effective for atmospheric correction.

\section{EXPERIMENTS}

The relations between MODIS derived SSST and NCEP/GDAS SSST for the typical atmospheric models of Tropic, Mid-Latitude Summer and winter and Sub-Arctic Summer are shown in Fig.4 to 7. In the experiments, 37, 18, 15 and 14 MODIS data which were acquired from 2000 to 2001 were used together with the match-up NCEP/GDAS data. 


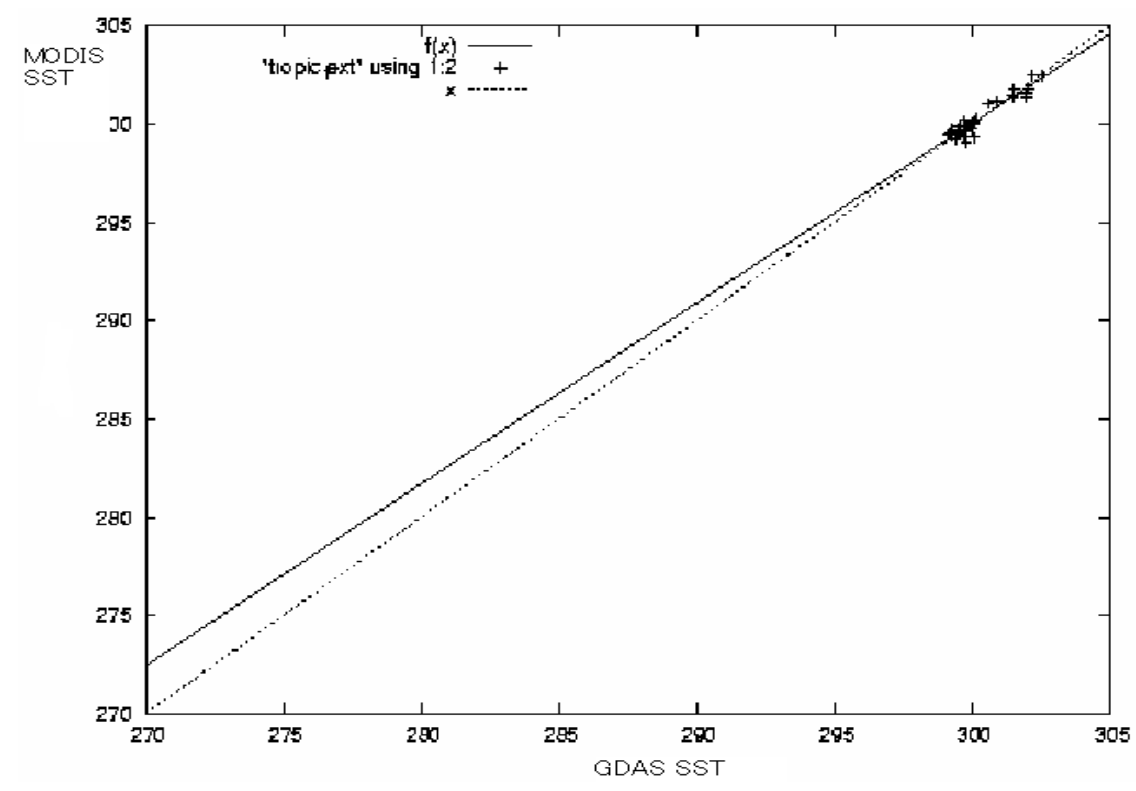

Figure 4 The relation between MODIS derived SSST and NCEP/GDAS SSST for Tropic ocean area.

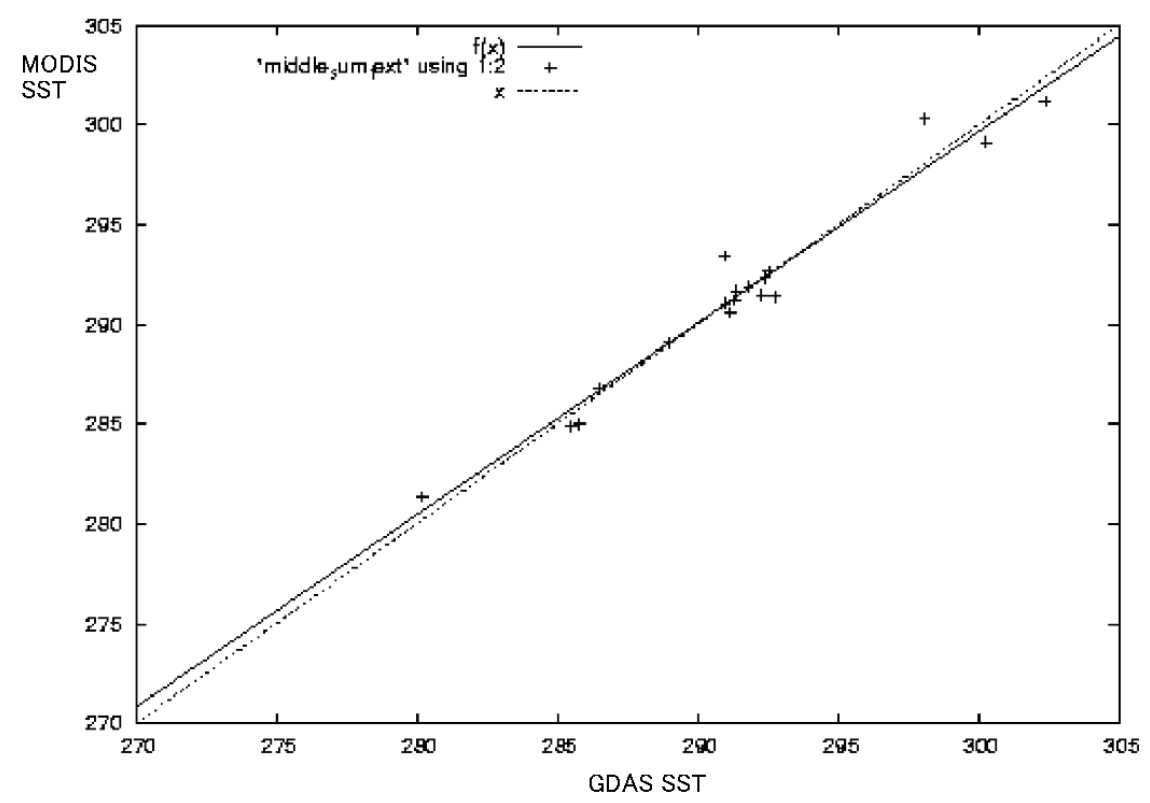

Figure 5 The relation between MODIS derived SSST and NCEP/GDAS SSST for Mid-Latitude Summer of ocean area and season 


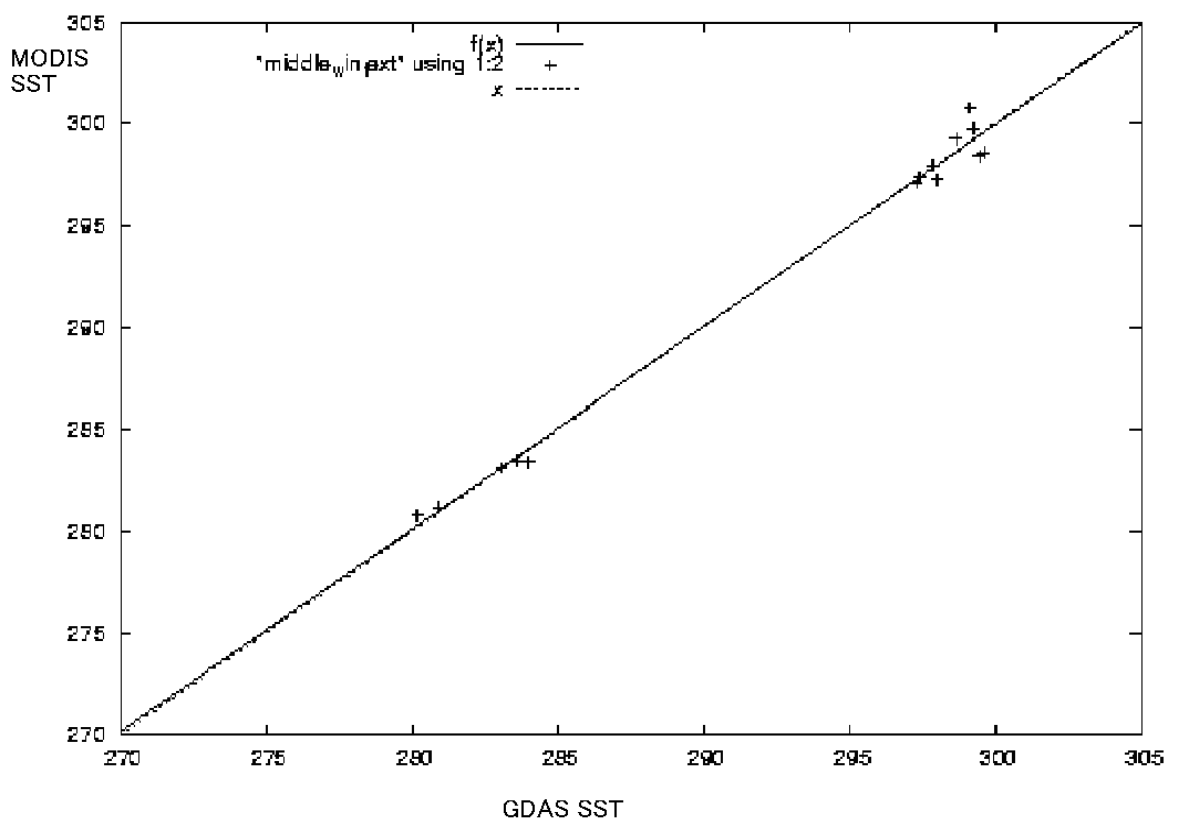

Figure 6 The relation between MODIS derived SSST and NCEP/GDAS SSST for Mid-Latitude Winter of ocean area and season

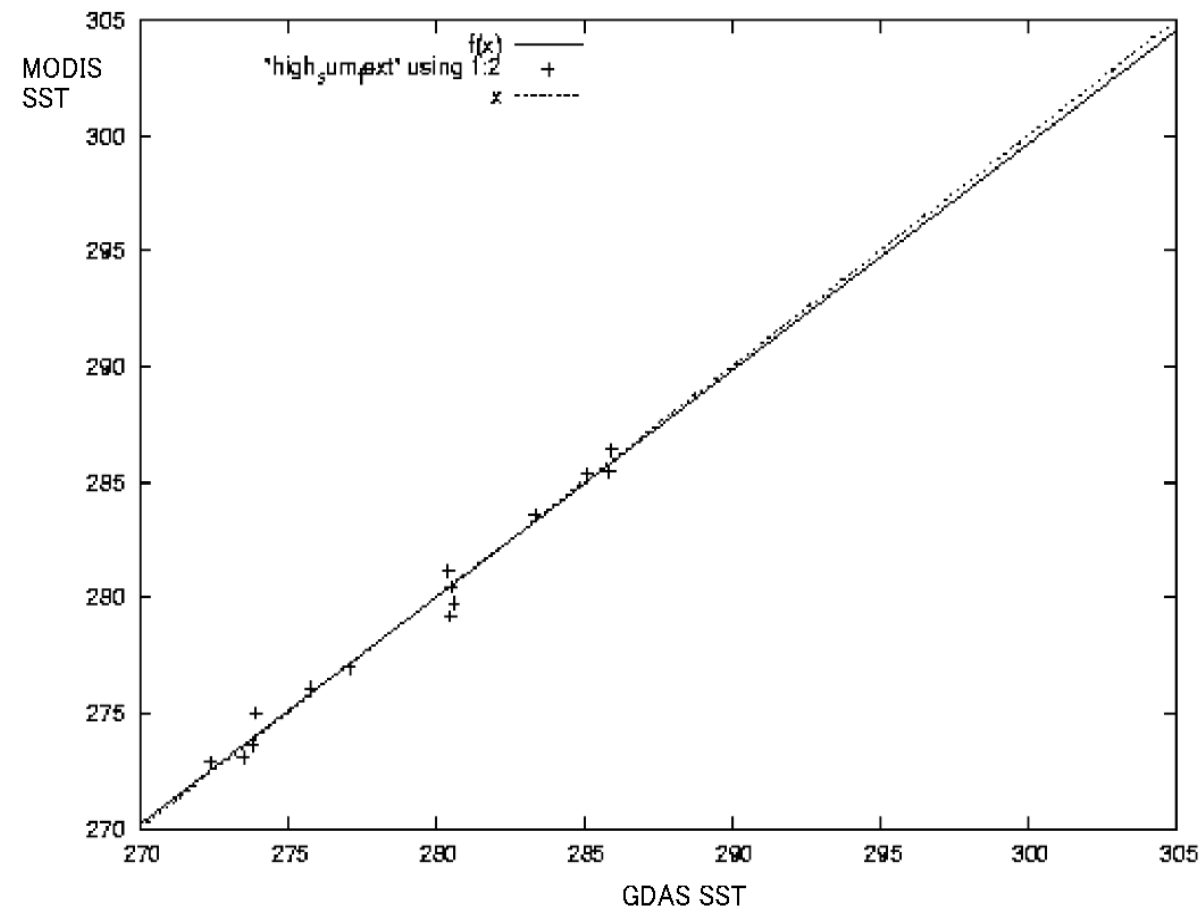

Figure 7 The relation between MODIS derived SSST and NCEP/GDAS SSST for Sub-Arctic Summer of ocean area and season

For all the ocean areas and seasons, in particular, for Tropic ocean area, it may concluded that MODIS derived SSST is lower than NCEP/GDAS derived SSST for the relatively high SSST portion while MODIS derived SSST is higher than that from NCEP/GDAS for the relatively low SSST portion. For the tropic ocean area, SSST ranges just from $298 \mathrm{~K}$ to $303 \mathrm{~K}$ while the ranges for the Mid-Latitude Summer and winter as well as Sub-Arctic Summer are 281$302 \mathrm{~K}, 280-299 \mathrm{~K}$ and $272-287 \mathrm{~K}$, respectively.

It is also found that the effectiveness of band 29 on RMSE improvement for Tropic model is greatest followed Mid-
Latitude Summer, Sub-Arctic Summer and Mid-Latitude Winter. This order is the same order of water vapor and aerosol content in the atmosphere as is shown in Fig.3 and 4.

\section{CONCLUSION}

It is found that SSST estimation accuracy with MODIS data is better than $0.417 \mathrm{~K}$ for all the cases defined above. A comparison of SSST estimation accuracy among the cases is attempted. Through regressive analysis, it is found that 0.305 to $0.417 \mathrm{~K}$ of RMSE can be achieved. 
Furthermore, it is also found that the effectiveness of exclusion of the band 29 of on RMSE degradation for Tropic model is greatest followed Mid-Latitude Summer, Sub-Arctic Summer and Mid-Latitude Winter. This order is the same order of water vapor and aerosol content in the atmosphere. RMSE of the regressive equation without band 29 ranges from 0.498 to $6.01 \mathrm{~K}$. Thus it is concluded that band 29 is effective to atmospheric correction (water vapor absorption). The effect corresponds to 30.6 to $38.8 \%$ of SSST estimation accuracy improvement.

If single set of regressive coefficients for all the cases is used, then SSST estimation accuracy is around $1.969 \mathrm{~K}$ so that the regressive equations with the specific five different cases, Tropic, Mid-Lat. Summer and winter and Sub-Arctic Summer and winter have to be used.

\section{REFERENCES}

[1] NASA, Science and mission requirements Working Report, EOS Science Steering Committee Report, Vol.I, 1990.

[2] Barton,I.J., Satellite-derived sea surface temperatures: Current status, Journal of Geophysical Research, Vol.100, pp.8777-8790, 1995. and Personal correspondence at the 37th COSPAR Congress, Warsaw, Poland, July 2000.

[3] Scott, N.A. and A.Chedin, A fast line-by-line method for atmospheric absorption computations: the automatized atmospheric absorption atlas, Journal of Applied Meteorology, Vol.20, pp.802-812, 1981.

[4] Hollinger, J.P, Passive microwave measurements of sea surface roughness, IEEE Trans. on Geoscience and Remote Sensing, Vol.GE-9, No.3, 1971

[5] Cox, C. and W.H.Munk, Some problems in optical oceanography, Journal on Marine Research, Vol.14, pp.68-78, 1955.

[6] Harris, A.R., O. Brown and M.Mason, The effect of wind speed on sea surface temperature retrieval from space, Geophysical Research Letters, Vol.21, No.16, pp.1715-1718, 1994.

[7] Masuda K., T.Takashima and T.Takayama, Emissivity of pure and sea waters for the model sea surface in the infrared window regions, Remote Sensing Environment, Vol.24, pp.313-329, 1988.
[8] Watte, P.D., M.R.Allen and T.J.Nightingale, Wind speed effect on sea surface emission and reflection for along track scanning radiometer, Journal of Atmospheric and Oceanic Technology, Vol.13, pp.126-141, 1996.

[9] McClain, E.P., W.G.Pichel and C.C.Walton, Comparative performance of AVHRR based multi-channel sea surface temperatures, Journal of Geophysical Research, Vol.90, No.C6, pp.11587-11601, 1985.

[10] Arai K.,K.Kobayashi and M.Moriyama, Method to improve sst estimation accuracy by means of linearized inversion of the radiative transfer equation, Journal of Remote Sensing Society of Japan, Vol.18, No.3, pp.272-279, 1998.

[11] Arai, K., Y.Terayama, M.Miyamoto and M.Moriyama, SST estimation using thermal infrared radiometer data by means of iterative method, Journal of Japan Society of Photogrammetory and Remote Sensing, Vol.39, No.1, pp.15-20, 2000.

[12] Arai, K., Influence due to aerosols on SST estimation accuracy for the non-linear iterative method, Journal of Remote Sensing Society of Japan, Vol.21, No.4, pp.358-365, 2001.

[13] US Air Force Geophysical Laboratory, MODTRAN 3 User Instructions, GL-TR-89-0122, 1996.

[14] NOAA/NGDC, ftp://ftp.ngdc.noaa.gov/pub/NCEP/GDAS/

[15] NASA/GSFC, http://picasso.oce.orst.edu/ORSOO/MODIS/code/ATBDsum.html\#SST

\section{AUTHORS PROFILE}

Kohei Arai, He received BS, MS and PhD degrees in 1972, 1974 and 1982, respectively. He was with The Institute for Industrial Science and Technology of the University of Tokyo from April 1974 to December 1978 also was with National Space Development Agency of Japan from January, 1979 to March, 1990. During from 1985 to 1987, he was with Canada Centre for Remote Sensing as a Post Doctoral Fellow of National Science and Engineering Research Council of Canada. He moved to Saga University as a Professor in Department of Information Science on April 1990. He was a councilor for the Aeronautics and Space related to the Technology Committee of the Ministry of Science and Technology during from 1998 to 2000. He was a councilor of Saga University for 2002 and 2003. He also was an executive councilor for the Remote Sensing Society of Japan for 2003 to 2005. He is an Adjunct Professor of University of Arizona, USA since 1998. He also is Vice Chairman of the Commission "A" of ICSU/COSPAR since 2008. He wrote 30 books and published 322 journal papers. 